\title{
ANALISA PREFERENSI KONSUMEN TERHADAP KERUPUK AMPLANG PRODUKSI TOKO OBIC DI KABUPATEN KETAPANG
}

\author{
Muh Anhar ${ }^{1}$, Adha Panca Wardanu ${ }^{2}$ \\ Perawatan Dan Perbaikan Mesin Politeknik Negeri Ketapang ${ }^{1}$ \\ Teknologi Pertanian, Politeknik Negeri Ketapang ${ }^{2}$ \\ J1. Rangga sentap Dalong sukaharja Ketapang \\ Email : anhar_dol@yahoo.com \\ Email : ap_wardhanu@yahoo.co.id
}

\begin{abstract}
Abstrak. Tujuan penelitian ini adalah Menganalisis karakteristik konsumen dan proses keputusan pembelian amplang merek OBIC, Menganalisis faktor-faktor yang mempengaruhi keputusan konsumen dalam pembelian amplang merek OBIC dan menganalisis sikap konsumen terhadap amplang merek OBIC. Jenis data yang digunakan dalam penelitian ini adalah data primer dan data sekunder. Metode pengambilan sampel yang digunakan adalah convenience sampling (pengambilan sampel secara kebetulan) yang termasuk ke dalam teknik pengambilan sampel non peluang. Karakteristik konsumen berdasarkan kelompok usia, jenis kelamin, jenis pekerjaan, pengeluaran per bulan, ketertarikan konsumen mengkonsumsi Amplang, asal informasi mengenai Amplang merek obic dan tempat konsumen biasa membeli Amplang merek obic dianalisis secara diskriptif. Penilaian sikap konsumen dianalisis dengan menggunakan Model Fishbein. Hasil Analisis diketahui bahwa karakteristik responden didominasi oleh perempuan. Usia terbanyak pada usia 21-30 tahun, tingkat pendidikan didomonasi oleh SLTA dan sebagian besar konsumen belum menikah. Pembelian Amplang OBIC oleh responden terjadi di tampat produksi. Setelah melakukan pembelian, konsumen mengevaluasi hasil pembelian dan hasilnya responden menyatakan puas terhadap Amplang OBIC. Reaksi konsumen apabila OBIC tidak tersedia di lokasi pembelian adalah membeli merek lain, dan apabila harga OBIC naik, maka konsumen akan memilih merek lain. Atribut yang dinilai positif adalah atribut higienis, rasa, aroma, harga dan kemasan. Atribut yang dinilai netral adalah atribut volume, warna dan kemudahan dalam memperoleh produk. Atribut produk yang netral, agar dinilai positif maka perlu terus meningkatkan pelaksanaan atau kinerja dari atribut tersebut. Secara keseluruhan atribut produk amplang OBIC dinilai positif oleh konsumen dengan nilai sikap sebesar 157,31. Hal ini menunjukkan bahwa atribut dari amplang OBIC diterima oleh konsumen.
\end{abstract}

Keywords: Amplang, Preferensi Konsumen, Perilaku Konsumen

\begin{abstract}
This study aimed at analyzing the characteristics of the consumers, what were their decisions and reasons of choosing amplang that was made by Obic store, and how the consumers' responds toward the Obic amplang.This study used primary and secondary data while the sampling method used was convenience sampling (sampling by chance). The characteristics of the consumers was on the basis of age, sex, occupation, education background, their budget per month, their interests in buying amplang, the source of information about Obic amplang they got, and the certain outlets where the consumers usually buys amplang were analyzed descriptively. Also, Fishbein model is used to assess the consumers' respond. The result of the analysis showed that the respondents were dominated by female. They are about 21-30 years old who are mostly the high school students and not married yet. Most of respondents usually bought the amplang in the place where it is produced. Moreover, the consumers were more interested in amplang produced Obic and they felt satisfied of it. However, the shortcoming was found when the Obic amplang was not available or sold, and its prices rised, most of consumers tended to buy the other brands of amplang. On the other hand, Obic amplang still had positive attribute, which are, hygienic, good taste and aroma, friendly price, and interesting packaging. Also, it had neutral attributed such as content, colour, and the availability of the product. It is suggested that the Obic amplang to improve the quality of its neutral attributes. Overall, the amplang from Obic is considered positive by consumers and it obtained 157,31 that is categorized 'acceptable' among the consumers.
\end{abstract}

Key Words: preference, amplang, consumers' responds. 


\section{PENDAHULUAN}

Kerupuk amplang merupakan jenis kerupuk ikan dengan bahan dasar daging, ikan tengiri, tepung tapioka, dan bahan tambahan seperti telur ayam, garam, gula, penyedap rasa, dan soda. Konsumsi Amplang cukup tinggi di Kota Ketapang, mengingat amplang merupakan makanan khas ketapang dan telah menjadi icon kota Ketapang.Salah satu produsen amplang yang ada di ketapang adalah OBIC, Amplang merek OBIC masih baru dipasaran perusahaan perlu mengetahui bagaimana perilaku konsumen terhadapAmplang untuk dapat menemukan strategi yang tepat untuk menghadapi persaingan. Pemahaman preferensi konsumen dapat dimanfaatkan dalamperumusan strategi pemasaran.Kotler (2000) menyatakan bahwa perusahaan harus membuat keputusan mendasar dalam pengetahuan pemasaran, bauran pemasaran dan alokasi pemasaran mentransformasikan strategi pemasaran menjadi program pemasaran. Persepsi setiap orang terhadap suatu objek akan berbeda-beda, oleh karena itu persepsi mempunyai sifat subjektif (Sutisna, 2001). Persepsi yang dibentuk oleh seseorang dipengaruhi oleh isi memorinya. Dengan demikian proses persepsi seseorang terhadap suatu objek dipengaruhi oleh pengalaman masa lalunya yang tersimpan dalam memori (Sutisna, 2001). Ciri khas atau karakteristik sosial dari objek yang dipersepsikan memegang peranan yang cukup besar (Sadli, 1985 dalam Sumarwan,2002). seseorang dapat muncul dengan persepsi yang berbeda terhadap objek rangsangan yang sama karena tiga proses yang berkenaan dengan persepsi, yaitu penerimaan rangsangan secara selektif, perubahan makna informasi secara selektif dan pengingatan sesuatu secara selektif. Konsumen merupakan fokus utama dari pemasaran. Konsumen sebagai individu atau kelompok yang berusaha untuk memenuhi atau mendapatkan barang atau jasa untuk kehidupan pribadi atau kelompoknya. Konsumen yang dipilih dalam penelitian ini adalah konsumen akhir (final consumer), yaitu setiap individu yang tujuan pembeliannya adalah untuk memenuhi kebutuhan sendiri atau untuk dikonsumsi langsung (Tambunan,2001). Sehingga pemahaman tentang konsumen lebih mengarah kepada proses pengambilan keputusan konsumen sendiri untuk memenuhi kebutuhan produk atau jasa.

\section{METODE PENELITIAN}

Penelitian preferensi konsumen terhadap Kerupuk Amplang OBIC ini dilakukan di wilayah Kota Ketapang. Pemilihan lokasi dilakukan secara sengaja (purposive) dengan pertimbangan Amplang merupakan salah satu makanan khas kota ketapang yang sangat di gemari, selain itu juga pertimbangan lain adalah bahwa daerah tersebut merupakan tempat produksi amplang. Pengambilan responden amplang OBIC difokuskan hanya di kecamatan Benua kayong dan Delta pawan kota Ketapang. Jumlah responden yang digunakan sebesar70responden. Penelitian ini menggunakan metodeJudgement Sampling dalam pengambilan responden.

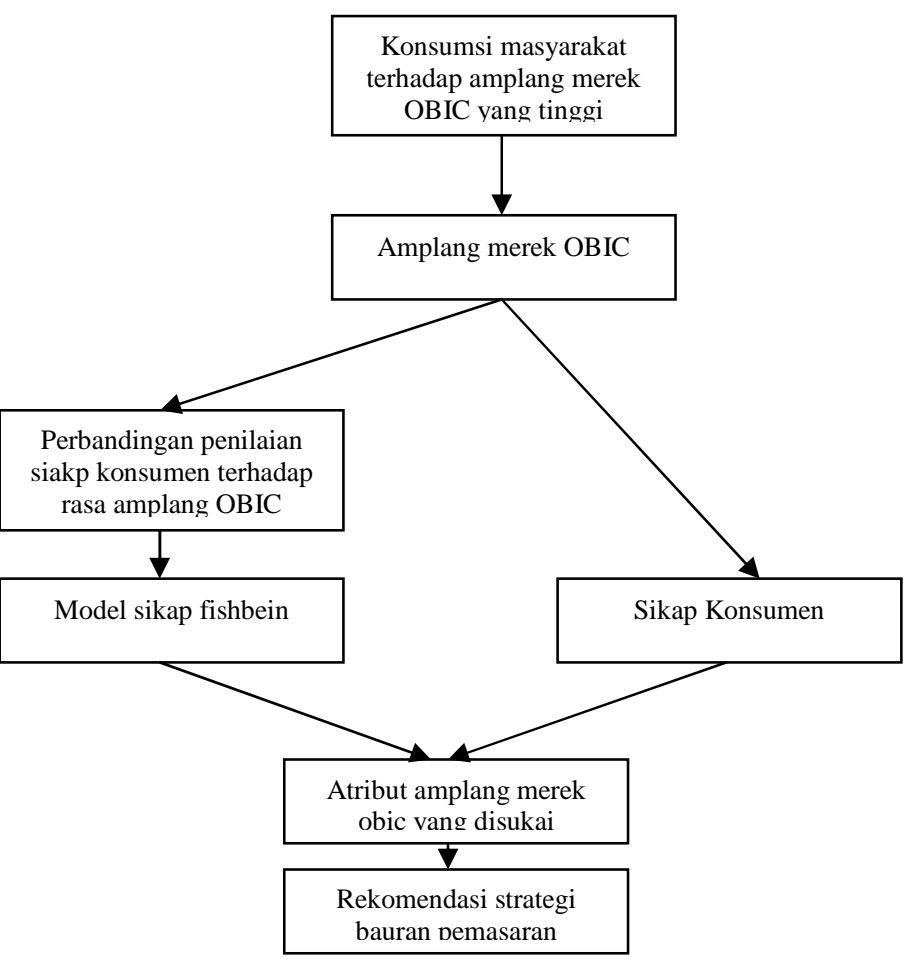

Gambar 1. Kerangka Penelitian

Pengambilan responden ini dilakukan dengan merumuskan terlebih dahulu kriteria-kriteria yang akan digunakan sebagai acuan dalam penarikan responden. Kriteria tersebut adalah responden yang pernah mengkonsumsi amplang merek OBIC. Penetapan kriteria tersebutagar responden dapat memberikan pendapat, jawaban serta pernyataan yang bermanfaat bagi penelitian ini.Data yang telah dikumpulkan diolah secara kualitatif dan kuantitatif. Pengolahan data menggunakan Microsoft Excel untuk tabulasi deskriptif yang menjelaskan proses keputusan pembelian secara umum dan SPSS 17 untuk mengetahui faktor-faktor yang mempengaruhi keputusan pembelian Ampang OBIC. Proses analisis data dalam penelitian ini menggunakan analisis deskriptif, dan multiatribut Fishbein.

\section{HASIL DAN PEMBAHASAN}

\subsection{Karakteristik Responden}

a. Jenis Kelamin

Jumlah responden amplang OBIC lebih banyak dikonsumsi oleh responden yang berjenis kelamin perempuan. Jumlah responden perempuan sebanyak 40 orang atau 57 persen, sedangkan jumlah 
responden laki-laki sebanyak 30 orang atau 43 persen. Responden yang mengkonsumsi amplang OBIC sebagian besar adalah perempuan, hal ini dikarenakan pihak perempuan merupakan pengambil keputusan utama dalam suatu keluarga.

b. Usia Responden

Responden yang banyak mengkonsumsi amplang OBIC adalah responden yang berada pada selang usia antara 21-30 tahun atau sebanyak 41 persen. Jumlah responden pada usia $\leq 20$ tahun sebanyak 11 orang, kisaran usia 31-40 sebanyak 23 orang dan usia >40 sebanyak 7 orang. Dari data tersebut menunjukkan bahwa pada semua selang usia memiliki nilai persentase yang tidak jauh berbeda. Hal ini menunjukkan bahwa amplang OBIC bisa dikonsumsi oleh semua jenis usia mulai dari remaja, dewasa hingga orang tua karena amplang tersebut merupakan makanan ringan yang umumunya dikonsumsi sebagai cemilan.

c. Pendidikan

Responden amplang OBIC didominasi oleh SLTA dan Diploma III masing-masing sebanyak 29 dan 30 persen. Pendidikan terakhir konsumen yang mengkonsumsi amplang OBIC terbanyak adalah Diploma dan SLTA, dimana kebanyakan responden tersebut sedang melanjutkan pendidikan kejenjang universitas yaitu sebagai mahasiswa. Kasali (2001) menjelaskan bahwa pendidikan yang berhasil diselesaikan konsumen bisa menentukan pendapatan dan kelas sosial seseorang. Selain itu, pendidikan juga menentukan tingkat intelektualitas seseorang. Pada gilirannya, tingkat pendidikan akan mempengaruhi pengambilan keputusan seseorang dalam pemilihan barang yang dikonsumsinya.

d. Pekerjaan

Jumlah responden dalam penelitian ini lebih banyak ditemukan pada mahasiswa yaitu sebanyak 36 persen. Persentase terkecil ditempati oleh wiraswasta yaitu sebesar 10 persen.

e. Status Pernikahan

Responden menurut status pernikahan adalah responden yang belum menikah sebesar 51 persen. Sedangkan jumlah responden yang sudah menikah adalah sebesar 49 persen. Berdasarkan wawancara kepada responden yang belum menikah, keputusan pembelian amplang OBIC umumnya dipengaruhi oleh diri sendiri. Sedangkan konsumen yang telah menikah keputusan pembelian dipengaruhi oleh anggota keluarga yang lain.

f. Tujuan Pembelian

Sebanyak 60 persen responden membeli amplang OBIC dengan tujuan untuk dijadikan oleholeh. Sebagian responden menyatakan bahwa amplang OBIC dapat dijadikan oleh-oleh khas kota Ketapang. Sebanyak 21 persen responden mengkonsumsi amplang OBIC sebagai makanan cemilan. Menurut responden amplang OBIC cocok sebagai cemilan setelah maupun bersamaan mengkonsumsi makanan. Sebanyak 6 persen responden membeli amplang OBIC untuk mendapatkan dijual kembali

g. Motivasi dan Penghalang Pembelian

Motivasi terbanyak responden dalam mengkonsumsi amplang OBIC adalah melihat orang lain membeli sebesar 74 persen. Responden memiliki motivasi tertentu dalam mengkonsumsi amplang OBIC, namun terdapat kendala yang menghalangi responden untuk memperoleh produk tersebut. Kendala utama yang dihadapi oleh responden adalah harga yang mahal (96\%) karena amplang OBIC diproduksi dengan menggunakan bahan baku ikan yang ketersediaannya tidak banyak dan harganya mahal. Kendala yang lain dalam memperoleh produk amplang OBIC adalah produk sulit diperleh (4\%).

h. Sumber Informasi Responden

Responden yang telah mengenali kebutuhannya dalam mengkonsumsi amplang OBIC, maka tahap selanjutnya adalah pencarian informasi untuk memberikan informasi yang lengkap mengenai produk tersebut. sumber informasi responden terbanyak berasal dari keluarga atau teman sebesar 62 persen. Sumber informasi yang berasal dari keluarga atau teman nilainya cukup tinggi karena biasanya informasi yang diperoleh melalui mulut ke mulut (word of mouth). Promosi produk amplang OBIC yang dilakukan oleh pihak produsen belum intensif. Hal tersebut dikarenakan selama ini promosi yang dilakukan melalui brosur yang disebar hanya pada acara-acara tertentu seperti pameran. Promosi melalui surat kabar tidak pernah dilakukan, oleh karena itu informasi yang berasal dari koran tidak ada.

Berdasarkan sumber informasi yang diperoleh, fokus perhatian responden terhadap amplang OBIC adalah rasa sebesar 47,14 persen. Atribut berikutnya yang menjadi fokus responden adalah harga amplang OBIC sebesar 29 persen. Atribut merek menjadi fokus perhatian yang terendah yaitu 3 persen hal ini dikarenakan produk amplang masih jarang ditemukan sehingga belum banyak merek yang dikenal oleh masyarakat.

i. Pertimbangan Responden Dalam Membeli Amplang OBIC

Faktor-faktor yang menjadi pertimbangan bagi responden untuk melakukan pembelian amplang OBIC adalah rasa, aroma, isi/volume, harga, merek dan kemasan. 11 responden lebih mempertimbangkan atribut rasa yang dimiliki oleh produk. Prioritas selanjutnya diikuti oleh atribut harga, kemasan dan merek serta isi. Jika harga yang dimiliki produk 
sesuai dengan yang diharapkan maka pertimbangan selanjutnya adalah isi/ volume, kemasan dan merek yang dimiliki produk. Bentuk kemasan amplang OBIC terdiri dari plastik dan aluminium foil. Responden lebih mempertimbangkan bentuk kemasan plastik sebesar 76 persen dan aluminium foil sebesar 24 persen. Pemilihan plastik yang dilakukan oleh responden dikarenakan harganya lebih murah dibandingkan dengan almunium foil. Responden yang memilih bentuk plastik karena warna dan bentuk amplang dapat dilihat langsung sehingga memudahkan pembeli untuk memilih.

j. Lokasi Pembelian

Hasil penelitian menunjukkan bahwa responden lebih banyak membeli di tempat produksi amplang OBIC sebesar 91 persen karena penjualan terbesar dilakukan ditempat produksinya, sedangkan di minimarket maupun toko yaitu 9 persen.

\subsection{Tingkat Kepentingan}

Tingkat kepentingan menunjukkan sejauh mana tingkat kepentingan suatu atribut menurut konsumen. Berdasarkan hasil penelitian memperlihatkan bahwa atribut higienis, rasa dan aroma merupakan atribut produk yang paling diperhitungkan oleh konsumen. Atribut higienis memiliki nilai 4,38, rasa memiliki nilai 4,25 dan atribut aroma memiliki nilai 4,06. Atribut higienis dinilai oleh responden sangat penting karena amplang Obic merupakan produk pangan yang dapat menjadi sumber penyakit apabila terkontaminasi oleh mikroorganisme patogen dan berakibat pada timbulnya masalah kesehatan. Untuk itu kebersihan produk (higienis) perlu diperhatikan sehingga memberikan rasa aman bagi konsumen yang mengkonsumsi amplang Obic. Atribut rasa dinilai sangat penting karena responden menginginkan rasa yang enak dan terasa khas ikan. Tingkat kepentingan atribut yang paling rendah adalah atribut kemudahan dalam memperoleh produk. Urutan tingkat kepentingan atribut dari skor tertinggi hingga terendah dapat dilihat pada Tabel 1.

Tabel 1. Nilai Kepentingan Responden Terhadap Atribut Amplang OBIC

\begin{tabular}{|l|c|c|c|}
\hline \multicolumn{1}{|c|}{ Atribut } & bi & $\begin{array}{c}\text { Kategori tingkat } \\
\text { Kepentingan }\end{array}$ & $\begin{array}{c}\text { Urutan } \\
\text { bi }\end{array}$ \\
\hline Higienis & 4,38 & Sangat Penting & I \\
\hline Rasa & 4,25 & Sanagt Penting & II \\
\hline Aroma & 4,06 & Penting & III \\
\hline Warna & 4,00 & Penting & IV \\
\hline Kemasan & 3,81 & Penting & V \\
\hline Harga & 3,72 & Penting & VI \\
\hline Volume & 3,68 & Penting & VII \\
\hline $\begin{array}{l}\text { Mudah } \\
\text { diperoleh }\end{array}$ & 3,56 & Penting & VIII \\
\hline
\end{tabular}

\subsection{Tingkat Kepercayaan}

Tingkat kepercayaan menunjukkan penilaian konsumen terhadap pelaksanaan atribut produk. Penilaian responden terhadap produk amplang Obic cukup baik karena tidak ada satu pun atribut produk Obic yang dinilai tidak baik. Hal ini dapat dilihat pada Tabel 2 bahwa nilai kepercayaan (bi) terhadap produk Obic bernilai positif.

Tabel 2. Nilai Kepercayaan Responden Terhadap Atribut Amplang OBIC

\begin{tabular}{|l|c|c|c|}
\hline Atribut & bi & $\begin{array}{c}\text { Kategori tingkat } \\
\text { Kepercayaan }\end{array}$ & $\begin{array}{c}\text { Urutan } \\
\text { bi }\end{array}$ \\
\hline Higienis & 4,60 & Sangat Baik & I \\
\hline Rasa & 4,44 & Sanagt Baik & II \\
\hline Aroma & 4,25 & Sangat Baik & III \\
\hline Harga & 4,13 & Baik & IV \\
\hline Kemasan & 4,13 & Baik & V \\
\hline Volume & 4,03 & Baik & VI \\
\hline Warna & 3,88 & Baik & VII \\
\hline $\begin{array}{l}\text { Mudah } \\
\text { diperoleh }\end{array}$ & 3,88 & Baik & VIII \\
\hline
\end{tabular}

Tingkat kepercayaan tertinggi diperoleh oleh atribut higienis dengan nilai kepercayaan sebesar 4,60. Hal ini menunjukkan bahwa Obic memberikan rasa aman bagi konsumen yang mengkonsumsinya. Kepercayaan responden terhadap atribut rasa juga dinilai sangat baik dengan nilai kepercayaan sebesar 4,44.

Tingkat kepercayaan terhadap atribut aroma dinilai sangat baik dengan nilai sebesar 4,25. Menurut responden amplang Obic dapat menimbulkan aroma ikan yang khas apabila mengkonsumsinya. Atribut kemasan memiliki tingkat kepercayaan yang sedang dengan nilai 4,13. Menurut responden bentuk kemasan dinilai layak karena kemasannya rapih sehingga tidak akan terjadi kebocoran isi produk. Namun ada juga responden yang mengatakan bahwa kemasan Obic kurang menarik. Tingkat kepercayaan atribut volume memiliki nilai sebesar 4,03 yang menunjukkan bahwa amplang Obic cukup konsisten dalam hal isi atau volume produk. Atribut dari peringkat terendah berturut-berturut adalah Kemudahan dalam memperolehnya, warna, dan volume memiliki tingkat kepercayaan yang sedang. Peningkatan atribut-atribut ini dapat dilakukan oleh pihak produsen agar tingkat kepercayaannya semakin baik.

\subsection{Sikap Konsumen Terhadap Amplang OBIC}

Penilaian responden secara keseluruhan terhadap Obic menyatakan sikap positif terhadap amplang Obic. Atribut amplang Obic yang dinilai positif, berturut-turut adalah higienis, rasa, aroma, 
harga dan kemasan. Sedangkan atribut yang dinilai netral oleh konsumen, berturut-turut adalah volume, warna, mudah diperoleh. Nilai sikap konsumen terhadap atribut amplang Obic dapat dilihat pada Tabel 3.

Tabel 3. Nilai Sikap Responden Terhadap Atribut Amplang OBIC

\begin{tabular}{|l|c|c|c|}
\hline \multicolumn{1}{|c|}{ Atribut } & Ao & $\begin{array}{c}\text { Kategori } \\
\text { Sikap }\end{array}$ & $\begin{array}{c}\text { Urutan } \\
\text { Ao }\end{array}$ \\
\hline Higienis & 20,13 & Positif & I \\
\hline Rasa & 18,87 & Positif & II \\
\hline Aroma & 17,27 & Positif & III \\
\hline Harga & 15,52 & Positif & IV \\
\hline Kemasan & 15,75 & Positif & V \\
\hline Volume & 15,36 & Netral & VI \\
\hline Warna & 14,83 & Netral & VII \\
\hline Mudah diperoleh & 13,82 & Netral & VIII \\
\hline \multicolumn{1}{|c|}{ TOTAL } & & & \\
\hline
\end{tabular}

Higienis dinilai sangat positif oleh konsumen, karena higienis dapat memberikan rasa aman ketika mengkonsumsinya. Atribut rasa dinilai positif oleh konsumen, karena menurut konsumen Obic memiliki rasa yang enak, dan rasa daging ikanya terasa. Meskipun rasa bersifat relatif, hal ini tergantung dari selera konsumen itu sendiri yang menyukai rasa ikan atau tidak. Terdapat lima atribut yang dinilai positif dan tiga atribut yang dinilai netral oleh konsumen. Untuk itu amplang Obic harus terus meningkatkan pelaksanaan atau kinerja dari atribut tersebut agar sikap konsumen terhadap amplang Obic semakin positif.Untuk menentukan skala penilaian tertinggi sikap dicari dengan skor sikap maksimum (ei bi max). Skor sikap maksimum adalah nilai maksimum yang didapat oleh masing-masing atribut yang ditawarkan jika responden memberikan penilaian tertinggi. Nilai tersebut diperoleh dengan cara mengalikan skor evaluasi (ei) dengan skor kepercayaan (bi) yang ideal yaitu 5. Skor sikap maksimum terhadap amplang Obic adalah sebesar 157,31. Nilai total sikap yang dicapai oleh atributatribut amplang Obic jika dibandingkan dengan skor sikap maksimum, maka nilai sikap responden tersebut pada kenyataannya masih jauh dengan penilaian skor sikap maksimum $(155,19<202)$. Hal tersebut dapat dikatakan bahwa kinerja atribut-atribut dari amplang Obic perlu lebih ditingkatkan lagi oleh pihak produsen. Skor Sikap maksimal responden terhadap amplang Obic dilihat pada Tabel 4.
Tabel 4. Skor Sikap Maksimal Responden Terhadap Atribut Amplang OBIC

\begin{tabular}{|l|c|c|c|}
\hline Atribut & ei & $\begin{array}{c}\text { bi } \\
\text { ideal }\end{array}$ & $\begin{array}{c}\text { Urutan } \\
\text { Ao }\end{array}$ \\
\hline Higienis & 4,38 & 5 & 21,88 \\
\hline Rasa & 4,25 & 5 & 21,25 \\
\hline Aroma & 4,06 & 5 & 20,31 \\
\hline Harga & 4,00 & 5 & 20,00 \\
\hline Kemasan & 3,81 & 5 & 19,06 \\
\hline Volume & 3,72 & 5 & 18,60 \\
\hline Warna & 3,68 & 5 & 18,40 \\
\hline $\begin{array}{l}\text { Mudah } \\
\text { diperoleh }\end{array}$ & 3,56 & 5 & 17,81 \\
\hline TOTAL & & & 157,31 \\
\hline
\end{tabular}

\section{KESIMPULAN}

1. Konsumen secara keseluruhan didominasi oleh perempuan. Usia Responden terbanyak pada usia 21-30 tahun, tingkat pendidikan konsumen didomonasi oleh SLTA karena sebagian responden berstatus mahasiswa (40\%). Karena banyak responden yang berstatus mahasiswa maka sebagian besar konsumen belum menikah. Amplang OBIC diperoleh dari keluarga atau teman. Pembelian Amplang OBIC oleh responden terjadi di tampat produksi. Setelah melakukan pembelian, konsumen mengevaluasi hasil pembelian dan hasilnya responden menyatakan puas terhadap Amplang OBIC. Reaksi konsumen apabila OBIC tidak tersedia di lokasi pembelian adalah membeli merek lain, dan apabila harga OBIC naik, maka konsumen akan memilih merek lain.

2. Atribut yang dinilai positif adalah atribut higienis, rasa, aroma, harga dan kemasan. Atribut yang dinilai netral adalah atribut volume, warna dan kemudahan dalam memperoleh produk. Atribut produk yang netral, agar dinilai positif maka perlu terus meningkatkan pelaksanaan atau kinerja dari atribut tersebut. Secara keseluruhan atribut produk amplang OBIC dinilai positif oleh konsumen dengan nilai sikap sebesar 157,31. Hal ini menunjukkan bahwa atribut dari amplang OBIC diterima oleh konsumen.

\section{REFERENSI}

Lestari, Eka Juwita. 2003. Analisis Preferensi Konsumen terhadap Produk Teh Celup Merek Gunung Mas : Studi Kasus di Kecamatan Makassar dan Pancoran DKI Jakarta. Skripsi. Jurusan Ilmu-ilmu Sosial Ekonomi Pertanian. Fakultas Pertanian. Institut Pertanian Bogor. 
Manuhutu, D. Andre. 2003. Analisis Ekuitas Merek Atas Merek-Merek Teh dalam Botol. Skripsi. Jurusan Ilmu-ilmu Sosial Ekonomi Pertanian. Fakultas Pertanian. Institut Pertanian Bogor.

Sihite, Y. 2000. Analisis Persepsi dan Preferensi Konsumen Teh Botol : Studi Kasus di PT Sinar Surya. Skripsi. Fakultas Teknologi Pertanian. Institut Pertanian Bogor.

Silalahi, Anggiat A. G. 2001. Analisis Perilaku Konsumen Teh Celup dan Implikasinya pada Strategi Bauran Pemasaran di daerah Kotamadya Bogor. Skripsi. Jurusan Ilmu-ilmu Sosial Ekonomi Pertanian. Fakultas Pertanian. Institut Pertanian Bogor.

Sumarwan, Ujang. 2002. Analisis Hubungan antara Persepsi Popularitas, Persepsi Kualitas, Persepsi Harga dengan Merek Teh Celup yang Dikonsumsi. Staff Pengajar Jurusan Gizi Masyarakat dan Sumberdaya Keluarga dan Magister Management Agribusiness. Fakultas Pertanian. Institut Pertanian Bogor.

Supranto, J. 2001. Pengukuran Tingkat Kepuasan Pelanggan. Edisi Kedua. PT Rineka Cipta. Jakarta.
Supriyasih. 2000. Analisis Pengendalian Persediaan Bahan Baku Teh Botol : Studi Kasus pada PT Sinar Sosro Jakarta. Skripsi. Jurusan Ilmuilmu Sosial Ekonomi Pertanian. Fakultas Pertanian. Institut Pertanian Bogor.

Susilowati, Uki. 2001. Analisis Perilaku Konsumen di Kota Bogor terhadap Teh Botol Sosro. Skripsi. Jurusan Ilmu-ilmu Sosial Ekonomi Pertanian. Fakultas Pertanian. Institut Pertanian Bogor.

Sutisna. 2001. Perilaku Konsumen dan Komunikasi Pemasaran PT Remaja ROSDA Karya. Bandung. Tambunan, Herlina. 2001. Analisis Perilaku Konsumen Produk Teh Siap Saji dan Implikasinya terhadap Strategi Bauran Pemasaran : Studi Kasus di PT Coca- Cola Amatil Indonesia. Program Pasca Sarjana. Jurusan Ilmu-ilmu Sosial Ekonomi Pertanian. Fakultas Pertanian. Institut Pertanian Bogor.

Yusastra, Riafitri. 1999. Analisis Sikap, Harapan, dan Evaluasi Konsumen terhadap Kerupuk Teh dalam Kemasan. Skripsi. Jurusan Gizi Masyarakat dan Sumberdaya Keluarga. Fakultas Pertanian. Institut Pertanian Bogor. 